\title{
VARIA
}

Mitja Skubic

Universidad de Ljubljana

\section{EL ESCRITOR ESLOVENO FRANCÈ BEVK Y SU VIAJE A ESPAÑA EN 1935}

En los últimos años en los artículos publicados en nuestra revista he llamado la atención sobre el conocimiento de España o de varios aspectos de ella por parte de algunas destacadas personalidades eslovenas de la esfera literaria y lingüística. En estas líneas se intentará aproximar al mundo cultural español al escritor esloveno Francè Bevk (18901970), no por su opus literario, sino sólo por haber escrito él un pequeño libro de menos de cien páginas sobre su breve viaje a España bajo el título Izlet na Špansko. Potopisne črtice - Viaje a España. Bosquejos de viaje, publicado por la editora LUČ, Unione Editoriale Goriziana, Gorizia 1936.

Es necesario presentar al escritor brevemente al mundo cultural español por no haber sido traducida ninguna de sus obras al español, aunque sí a casi todas las lenguas eslavas, al italiano, francés y rumano, al inglés, alemán y danés, al húngaro y albanés. Francè Bevk nació en 1890 en el distrito de Gorizia que en aquel entonces formaba parte del imperio austro-húngaro. En 1913 terminó sus estudios en la escuela normal de maestros de Gorizia, en aquel entonces capital de un ducado de la vieja Austria, y después del fin de la primera guerra mundial en 1918 se quedó en Gorizia como personalidad cultural, periodista, redactor de varios diarios eslovenos, entre ellos también de un periódico satírico. Esta última tarea le procuró varias veces breves encarcelamientos. Es de saber que este territorio, igualmente como el de Trieste y de toda la península de Istria, desde 1918 formó parte del Reino de Italia. A causa del pacto secreto de Londres de 1915, estipulado entre Italia y las potencias aliadas Rusia, Francia e Inglaterra, Italia por su entrada en la guerra al lado de los aliados obtuvo también áreas del derrotado imperio austro-húngaro que no eran italianas o por lo menos no italianas por completo, como la zona del antiguo condado de Gorizia, étnica y lingüísticamente mayormente eslovena. La situación de las etnias eslovena y croata bajo la dominación italiana no era fácil y se agravó con la llegada al poder del fascismo en Italia después de 1922. Con la reforma escolar de 1923 - la llamada reforma Gentile, por el nombre del ministro que la realizó, - el italiano llegó a ser la única lengua de enseñanza en el primer año de las escuelas de todos los grados y en los años siguientes se extendió también a los cursos superiores, eliminando el esloveno (y el croata en Istria) de la escuela por completo. El uso del esloveno fue prohibido en la vida pública y hasta en la iglesia fue decretado predicar en italiano. Desde ese aspecto merece la pena mencionar la novela de Francè Bevk Kaplan Martin Čedermac - El capellán Martin Čedermac; un cuento realista sobre las dificultades y la aflicción de la etnia eslovena y también del clero esloveno: no se podía ni predicar ni escuchar la predicación en lengua materna. Por obvias razones Bevk publicó la novela en Ljubljana, en 1938, y bajo un seudónimo.

Toda esta amplia introducción me pareció necesaria para encuadrar al escritor en el espacio y tiempo en el cual vivió y creó. Bevk, ciudadano italiano de nacionalidad es- 
lovena, buscó y obtuvo el visado italiano para España a fin de poder participar en el congreso del PEN-club, celebrado en mayo de 1935 en Barcelona, lo que le había sido negado tres años antes en ocasión del congreso precedente, en Dubrovnik. Es probable que intervinieran en su favor los colegas escritores italianos, quizás el mismo Marinetti, poeta futurista, presidente del PEN italiano en aquel entonces, miembro importante del partido fascista. Así, Bevk participó en el congreso del PEN y, después de su regreso a Gorizia, publicó una breve relación de su viaje. El mismo escritor explica que, aunque el objeto de su viaje haya sido la participación en el congreso, del congreso en el relato no quiere hablar, sino que quiere simplemente presentar a sus compatriotas el viaje y sus impresiones sobre algunas ciudades y sitios españoles importantes. No es sorprendente su silencio sobre la situación social y política de la España de entonces. Bevk, personalidad de clara inclinación izquierdista, evitó pronunciarse sobre el cambio esencial que se verificó justamente en aquel tiempo en la sociedad española: cada análisis de los problemas políticos y sociales hubiera imposibilitado la publicación en Gorizia. La censura italiana fue más que severa y la publicación de un libro esloveno, por el mero hecho de estar escrito en esloveno, fue un problema.

El mismo escritor afirma varias veces que escribe sólo de sus impresiones al visitar el país y que actúa como mediador entre éstas y el lector. Una sola vez se aleja de esta línea. Hablando de los teatros en Madrid, muestra la amplia paleta de sus sólidos conocimientos del teatro español. El congreso del PEN se celebró precisamente a los trescientos años de la muerte de Lope de Vega. Bevk, así parece, es un gran aficionado de su creación teatral y le adjudica a Lope de Vega el hecho de ser un gran conocedor del alma española, tanto de sus aspectos claros como de los sombríos. Bevk casi pide excusas al lector por consagrar, en un relato de viaje, un extenso espacio al gran dramaturgo español porque, dice Bevk, en las obras de Lope de Vega se respira la vida auténtica de todas las capas de la sociedad española.

El escritor esloveno, por lo visto, estuvo por primera vez en España. Visitó muy atentamente Barcelona y Madrid y lamentó no haber podido bajar al Sur para ver Andalucía. Se pregunta si en un futuro le será posible repetir su viaje. De todos modos, se fue a España bien preparado, por haber aprendido mucho sobre el país en una obra de Salvador de Madriaga. De los viejos tiempos hace mención de las romerías de los peregrinos eslovenos a Santiago de Compostela. Y resulta manifiesta su sed de ver lo más posible. Le encantó Barcelona, sobre todo su barrio gótico, recuerda el hervidero de la gente en las Ramblas, la Sagrada Familia y la Pedrera de Gaudí. En el libro aparece un buen número de fotografías. Visitó Tibidabo y Montjuich: los organizadores del congreso tuvieron la feliz idea de ofrecer a los congresistas extranjeros en el castillo de Monjuich un espectáculo de bodas folklóricas. En cuanto al encuentro entre las culturas de las dos etnias, Bevk recuerda en su escrito que la guardia civil que estaba delante del municipio llevaba traje catalán y que algunos edificios tenían además de la bandera nacional también la catalana. Para la Plaça de Catalunya aduce también el nombre castellano. Como Bevk provenía de una ciudad donde toda la vida pública era monolingüe, esto es, donde oficialmente y en la vida cultural sólo se podía usar el italiano le quedó impreso en la memoria el hecho de que los periódicos se publicaban en las dos lenguas y de que las piezas teatrales se anunciaban en castellano y en catalán. En Madrid le encantó a Bevk El Prado con su alto valor de cuadros tanto de las obras del Renacimiento italiano, a empezar con las obras maestras de Fra Angélico, de Rafael, de Tiziano, como del arte español. Desde Madrid se permitió una breve excursión al Escorial que no le dejó ninguna impresión, a 
excepción de las habitaciones de Felipe II. Todo lo contrario ocurrió con Toledo. Le reservó a la encantadora ciudad a orillas del Tajo la última jornada de su estancia madrileña y en aquel día se embebió del arte español: la vieja sinagoga Santa María la Blanca, la catedral gótica, San Juan de los Reyes e, inevitablemente, El Greco con El funeral del conde de Orgaz en la capilla de Santo Tomás.

El escritor esloveno Francè Bevk describe su viaje por España y, por cierto, no se olvida de la gente: juzga los españoles tranquilos, apacibles y, según lo que él pudo constatar, no divididos en capas sociales, sino más bien ligados por vínculos de amistad. No siempre se limita a un puro relato turístico: a veces explica algunas palabras españolas (limpiabotas), para otras añade la pronunciación correcta (El Tajo), y en la descripción turística introduce de vez en cuando un recuerdo personal: así por ejemplo el del carbonero en Tarrasa que dejó su carreta en medio de una calle estrecha, y se perdió por cierto tiempo de modo que el autocar con los congresistas tuvo que esperar pacientemente. Un recuerdo sincero y cordial entre muchos otros que le acercó España a Bevk y la hizo aún más querida.

\section{FRANCÈ BEVK: IZLET NA ŠPANSKO (1936)}

Pisatelj Francè Bevk se je udeležil kongresa evropskega PEN-kluba v Barceloni v maju 1935 in je naslednjega leta v Gorici, pri slovenski založbi LUČ, objavil svoje spomine na sicer kratko bivanje v Španiji z naslovom Izlet na Špansko - Potopisne črtice. Pisatelj kar na začetku pove, da ne bo govoril o kongresu, da piše z namenom, da približa to deželo svojemu bralcu in da bo opisal nekaj španskih mest in znamenitosti v njih. Ni presenetljivo, da Bevk nikjer ne govori o socialnih ali političnih razmerah v Španiji, saj je bil tam v času 2. republike; vsakršno tehtanje razmer ali celo poveličevanje uspehov tedanje levičarske vladavine bi v Gorici objavo onemogočilo. Močno čustvena pa so Bevkova opažanja v Barceloni, da so namreč knjige in časopisi v kastiljščini in katalonščini, da so tudi gledališke predstave $\mathrm{v}$ obeh jezikih in da tudi $\mathrm{v}$ javnem življenju katalonščina diha s polnimi pljuči. Bilo bi presenetljivo, da bi v svoji predstavitvi kulturnega življenja v Barceloni tega ne povedal, saj je prihajal iz mesta, kjer je uradno eksistiral en sam jezik, kjer naj bi torej ne bilo ne slovenščine ne furlanščine. 